\title{
Steel-Concrete Composite Bridges: Design, Life Cycle Assessment, Maintenance, and Decision-Making
}

\author{
D. Martínez-Muñoz $\mathbb{D}$, J. V. Martí $(\mathbb{D}$, and V. Yepes $\mathbb{1}$ \\ ICITECH, Department of Construction Engineering, Universitat Politècnica de València, Valencia 46022, Spain \\ Correspondence should be addressed to D. Martínez-Muñoz; damarmu1@cam.upv.es
}

Received 20 March 2020; Revised 16 April 2020; Accepted 18 April 2020; Published 28 May 2020

Academic Editor: Mario D’Aniello

Copyright ( 2020 D. Martínez-Muñoz et al. This is an open access article distributed under the Creative Commons Attribution License, which permits unrestricted use, distribution, and reproduction in any medium, provided the original work is properly cited.

\begin{abstract}
Steel-concrete composite bridges are used as an alternative to concrete bridges because of their ability to adapt their geometry to design constraints and the possibility of reusing some of the materials in the structure. In this review, we report the research carried out on the design, behavior, optimization, construction processes, maintenance, impact assessment, and decision-making techniques of composite bridges in order to arrive at a complete design approach. In addition to a qualitative analysis, a multivariate analysis is used to identify knowledge gaps related to bridge design and to detect trends in research. An additional objective is to make visible the gaps in the sustainable design of composite steel-concrete bridges, which allows us to focus on future research studies. The results of this work show how researchers have concentrated their studies on the preliminary design of bridges with a mainly economic approach, while at a global level, concern is directed towards the search for sustainable solutions. It is found that life cycle impact assessment and decision-making strategies allow bridge managers to improve decision-making, particularly at the end of the life cycle of composite bridges.
\end{abstract}

\section{Introduction}

Bridges are one of the most important structural typologies made by civil engineers and have a great impact on society by favoring territorial connection. The design of bridges must integrate different requirements to reach a design according to the required needs. In addition, the design of bridges must consider the context in which the structure is framed. This context is related to the characteristics of the place where the structure will be located and the determining factors from economic, cultural, and environmental point of views.

Engineers are faced with making designs that must take into account factors that go beyond the simple fact that their work fulfils the function for which it is designed [1]. In bridge design, other aspects, such as the construction process or the structure's reuse or demolition strategies, must be evaluated. This requires a clear understanding of the behavior and stresses that their materials will be subjected to throughout their service life [1]. In addition, these infrastructures have an associated environmental impact during their construction [2] that must also be considered. This impact can be mitigated with good design and planning [3]. Since the World Commission of Environment and Development defined sustainable development guidelines [4], national policies have focused on obtaining infrastructures that accomplish the sustainable development terms. In addition, the United Nations defined the Sustainable Development Goals [5] as objectives for 2030. Because of this, it can be understood that one of the demands of society is the incorporation of sustainability in infrastructure design. De Jong [6] adds environmental friendliness as one of their design principles. Furthermore, innovation in building materials and structural shapes give designers more tools to make designs more in line with current design criteria. In Figure 1, the scheme of design criteria have been displayed.

To achieve the objectives of the current design, steelconcrete composite bridges (SCCBs) can be a good alternative due to the recyclability of the steel parts of the structure [7]. SCCBs have been used extensively since the $20^{\text {th }}$ century, when composite structure theories were developed more generally [8]. In addition, Musa and Diaz state 


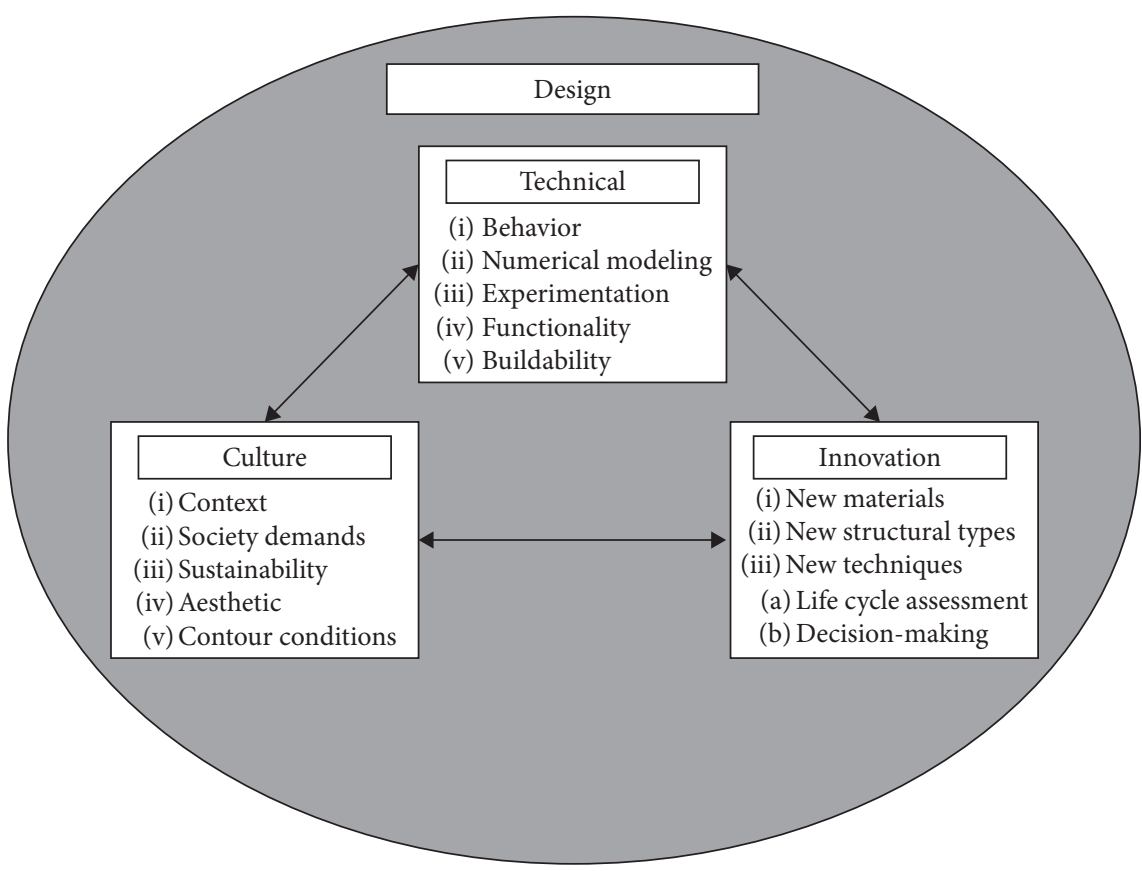

FIgURE 1: Scheme of design criteria.

that this type of bridge is highly efficient due to the possibility of placing the steel and concrete in the parts of the cross section where they perform best. They also provide added value due to their attractive appearance [9].

The aim of this review is to collect knowledge regarding SCCBs to identify the approach that designers and researchers have given to design. This work provides designers and technicians with a guide where current information is collected regarding the behavior of this type of structure, the methods used by authors to reach the optimum design, the construction methods and maintenance, as well as the repair strategies. Furthermore, a lack of knowledge related to SCCBs is found, offering researchers the possibility of focusing their efforts on the weakest areas. The gaps are obtained by using statistical techniques that analyze the correlation between different variables. Furthermore, all the information considered in this study gives a broader vision of the possibilities of the sustainable design of SCCBs, considering sustainability in the whole process.

\section{Data Sampling Strategy}

The searches related to the subject of this work were carried out with the scientific bibliographic databases of SCOPUS and the Web of Science. The search period was limited from 1995 to 2019. The terms used for the search of the different articles were the combination of "Steel-concrete composite bridges" with the following words: "Optimization," "Decision making," "Multi-attribute decision making," "Multi-target decision making," "Multi-criteria decision making," "Life cycle assessment," "Life cycle, "Maintenance," "Fatigue," "Reliability," "Uncertainty," "Robustness," "Fire resistance," "Construction process," "Safety," "Strength," "Seismic" and "Buckling," finding a total of 4784 articles.
In order to filter the works that are directly related to the relevant topics, a first exclusion criterion was applied considering only peer-reviewed scientific papers and conference works. In addition, studies that do not consider the complete composite action of the structure or that deal with the behavior of independent composite elements were discarded. Finally, we only considered articles written in English for this study. This screening strategy resulted in 90 articles.

2.1. Statistical Analysis. To identify the fields that have been extensively studied and those that present a lack of knowledge, a simple correspondence analysis was carried out using IBM SPSS Statistics 25 (IBM Corp., Armonk, NY, USA) software [10]. This method allows us to represent the relationship between two variables. In this case, it was used to relate the fields of knowledge related to the design with the type of section of the SCCB and the stages of the design process. This statistical method has been applied in other literature review studies [11].

\section{Steel-Concrete Composite Bridge Design}

3.1. General Overview. SCCBs have been studied extensively due to the good behavior of this type of structure. The information obtained from the literature review was divided into six fields of study: Design and Behavior, Optimization, Construction Process, Maintenance and Repair, Life Cycle Assessment (LCA), and Multi-Criteria Decision-Making (MCDM). This division is not arbitrary. The division is related to the sustainable design phases that Penadés-Plà et al. and others proposed in their work [11]: Planning and Design, Construction, Operation and Maintenance, and Demolition and Recycle. 
The first stage encompasses the Design and Behavior field of knowledge, where researchers study the behavior of the structure and propose calculation methods and structural solutions to improve the behavior of specific areas or the whole set. In the next phase of the process, designers use techniques to achieve better solutions and study how to bring their designs to reality. At this stage of the design process, the optimization and construction processes play a crucial role and must be considered together to reach the best solution for the construction phase. Once the structure materializes, the design should consider maintenance periods and methods to evaluate the condition of the structure, in order to assess the actions to be taken, either for repair or maintenance. When the service life has come to an end, the construction has to be demolished and recycled. All these processes and decisions have an associated impact, which is where the LCA method allows technicians to assess the impact of the structures. Throughout the design process, decisions have to be made to reach the best solution for each stage. MCDM methods offer a powerful tool for designers to select the solution that most closely matches the constraints [12].

In addition, the SCCBs found in the articles of this review can be grouped by the type of cross section into three categories, plate girder, twin girders, or box girder, according to the classification of Vayas and Iliopoulos [13]. In Figure 2, the three bridge sections described are displayed. The plate girder bridge consists of a number of steel girders that are connected to a concrete slab by shear connectors that allow composite behavior. The twin girders bridge has two or more steel girders that are usually I-shaped girders, which, like the plate girder bridge, are connected to a concrete slab. The difference between the slab bridge and the beam bridge is the behavior of the steel beams. On the one hand, slab bridges have a larger number of smaller beams. Because of their slenderness, these beams are classified as class 1 or 2 sections according to the Eurocodes [14]. On the other hand, in beam bridges, the larger dimensions of the beams make it impossible for the steel beams to behave as class 1 or 2 ; sections these are classified as class 4 sections and a reduction must be taken into account for calculations [14]. The geometry of the concrete slab is also reduced considering an effective width due to the phenomenon of shear lag according to regulations [14]. Finally, the box girder bridge is made up of an open steel box girder connected to a concrete slab on the top. The difference lies in the torsional behavior of this type of cross section, which is better than for twin girders bridges [9].

The distribution of studies found in every field is displayed in Figure 3. As shown, the greatest number of studies is focused on the Design and Behavior of bridges (66\%), followed by the Optimization (13\%) and the LCA (8\%). Furthermore, the studies can be grouped by the year of publication and research field, as shown in Figure 4 . The period of greatest production related to SCCBs was between 2010 and 2019. In 2019, there was a change in trend, with more studies carried out in fields related to optimization and decision-making instead of continuing with the study of the behavior of bridges and the generation of new designs.

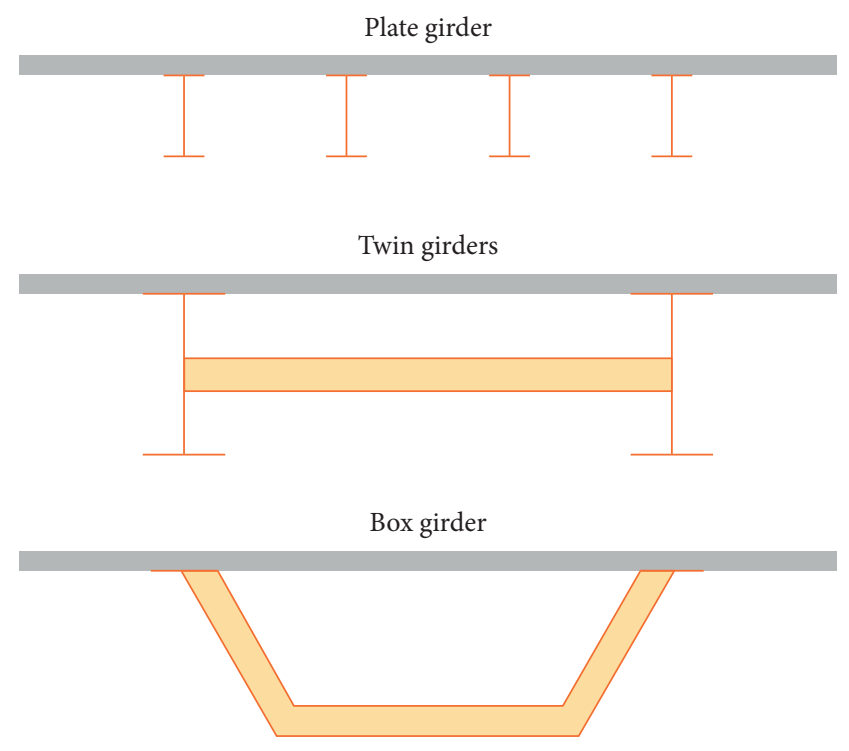

Figure 2: Bridge cross sections considered.

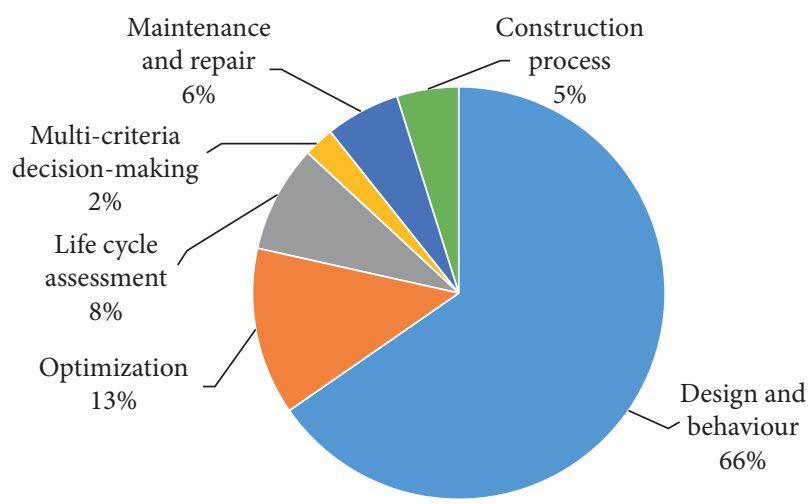

FIgURE 3: Distribution of publications in every research field.

3.2. Design and Behavior. The field of design and behavior includes all the studies related to the behavior of SCCBs towards traffic loads, torsion, fire, fatigue, and seismic actions. In addition, this field includes new designs proposed by authors for the global design of the bridge deck or other local parts that have unique behavior.

In this field, three main approaches have been found: design proposals, behavior studies and calculation methods. Design proposals are focused on the conception of new geometries or the distribution of materials that improve the behavior of SCCBs [15-25]. Behavior studies are centered on the application of experimental or numerical approaches to study the bridge response when submitted to fire [26-30], seism [31-39], fatigue [40-52], secondary torsion [53], vibrations [54-59], blasting loads [60], or other phenomena [61-67]. Alternatively, some authors have focused their studies on implementing new calculation methods for SCCBs [68-75].

Table 1 summarizes the studies carried out for bridge design, with the majority of the studies dealing with proposals for the design of bridge cross sections and shear connectors. The most studied cross section type is the box girder. 


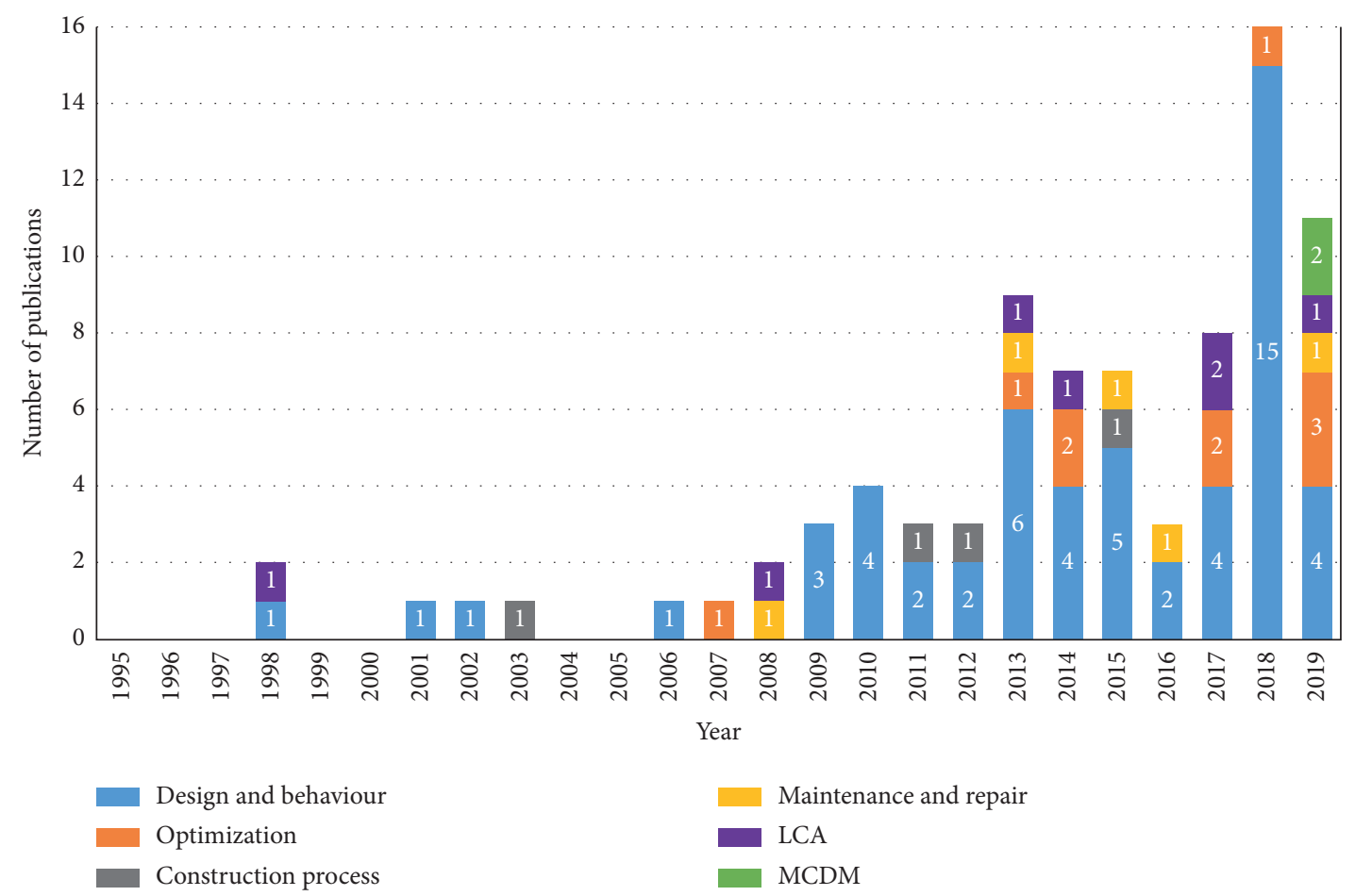

Figure 4: Number of publications grouped by year and research field.

TABLE 1: Summary of SCCB design publications.

\begin{tabular}{lcccc}
\hline Ref. & Author & Topic & Cross section & Method \\
\hline$[15]$ & Nakamura et al. & Cross section designs & Twin girders & Experimental \\
{$[16]$} & Kim and Jeong & Cross section and shear connector design & Plate girder & Experimental and numerical \\
{$[17]$} & Xie et al. & Steel sections depth for midspan in concrete bridges & Box girder & Numerical \\
{$[18]$} & Kim and Jeong & Cross section and shear connector design & Plate girder & Experimental and numerical \\
{$[19]$} & Vasseghi & Shear connectors in negative bending region & Plate girder & Numerical \\
{$[20]$} & Shao et al. & Cross section design with reactive powder concrete & Box girder & Experimental and numerical \\
{$[21]$} & Wu et al. & Cross section U-shaped design & Box girder & Experimental and numerical \\
{$[22]$} & Nie et al. & Corrugated steel web cross section & Box girder & Experimental \\
{$[23]$} & Esteves et al. & Union between concrete and composite sections & Box girder & Numerical \\
{$[24]$} & Peng-Zhen et al. & Negative bending region & Twin girders & Experimental \\
{$[25]$} & Xie et al. & Steel sections length for midspan in concrete bridges & Box girder & Numerical \\
\hline
\end{tabular}

According to the amount of studies found, it can be seen that work is focused on analyzing the behavior of SCCBs. Fire resistance studies are focused on modeling fire action with numerical models [26, 30] or fluid mechanics [27]. Other studies, related to the analysis of the fire behavior of SCCBs, have also carried out experimental tests to calibrate the numerical models [28, 29]. However, all the authors conclude that there are very few studies on the fire behavior of SCCBs. This lack of studies is also reflected in issues such as blasting loads [60] or the torsional behavior of curved SCCBs [53]. On the contrary, the behavior of SCCBs to fatigue and seism has been largely studied.

Studies related to new calculation methods focus on adding new concepts to the design of SCCBs. Zona et al. [68] proposed a probabilistic nonlinear analysis method for bridge design using the first-order second-moment approximation [76] and the direct differentiation method [77-80] for the sensitivity analysis. Nie and Zhu [70] created a beam-truss model for box girder SCCBs based on classical shear-flexible grillage analysis, obtaining a $10 \%$ difference between this model and traditional ones. Jia et al. [72] included in their method the system reliability to failure with a ten-degree-of-freedom finite element model. Other authors have focused their method on evaluating the shear lag [69], shrinkage, creep and cracking [73], or flexural lateral loads $[74,75]$.

3.3. Optimization. The design of structures is based on the search for solutions that allow the structures to be able to fulfil their function using as fewer resources as possible. The designers use an iterative process that consists of the modification of the geometry and a later verification to arrive at a better design of the structure. This procedure is clearly based on the experience and judgement of the designer. Researchers have developed different methods to 
achieve optimal structures by means of algorithms. These procedures guide the search for optimal solutions by changing the variables that define the structure. The acceptance of new solutions depends on the value of the objective function and the characteristics of the algorithm. These optimization methods have been applied to all types of structures, including bridges [81-84].

Some researchers have focused their studies on the search for optimum designs, taking as an objective the cost reduction of the structure [85], starting from basic studies carried out by applying techniques that include penalty functions for the search of the optimum [86]. Since then, techniques have become increasingly more complex, with the use of optimization algorithms, like in the study of Musa and Diaz [9] who used the Excel optimization module to reach a preliminary design without cracking and fatigue checks. The optimization process generally uses a numerical model to evaluate the stresses of the bridge, which has a high computational cost, with the authors having developed methods that divide the optimization process into two stages. Briseghella et al. [87] used a simple model to reach the optimum geometry with the Ansys optimization tool and later applied topological optimization [88-92] to a more complex numerical model using the finite element method to reduce the steel sections that are subjected to local buckling.

Pedro et al. [93] applied different algorithms in a twostage optimization process. The results of their analysis gave good behavior for the optimization techniques for SCCB optimization, with good results. Other authors have applied the fmincon Matlab functions [94] to SCCB I girder bridges, taking good results for span lengths up to $20 \mathrm{~m}$. In other studies, the life cycle cost of the structure were evaluated, comparing the SCCB solution with prestressed concrete solutions and stating that the prestressed concrete solutions are better than the composite ones [95]. These results could depend on the life cycle phases that have been considered. Rempling et al. [96] propose a set-based parametric design $[97,98]$ applied to SCCB optimization. Kaveh et al. applied and compared different algorithms to composite bridges in their studies successfully $[99,100]$. The optimization techniques are summarized in Table 2.

Nowadays, the value of structures is assessed not only by their economy but also by their social and environmental impact. Optimization studies carried out in the current literature focus on the optimization of a single objective and fundamentally on the reduction of weight and therefore on an economic improvement. The social and environmental pillars of sustainability are not studied from the point of view of optimization. Furthermore, in studies carried out on concrete bridges, multi-objective optimization has been applied [112, 113], while in SCCBs, these methods are not applied, nor are those of accelerated optimization [114]. Therefore, it can be said that there is a lack of knowledge in the field of multi-criteria optimization and the use of methodologies that allow the optimization of the structure from a social and environmental point of view for the SCCBs. Moreover, the approach given to the optimization of structures consists mainly of the application of different
TABLE 2: Optimization techniques used by authors.

\begin{tabular}{|c|c|c|c|}
\hline Ref. & Author & $\begin{array}{c}\text { Cross } \\
\text { section }\end{array}$ & Method \\
\hline [100] & $\begin{array}{l}\text { Kaveh and } \\
\text { Zarandi }\end{array}$ & $\begin{array}{l}\text { Box } \\
\text { girder }\end{array}$ & $\begin{array}{c}\text { Colliding bodies } \\
\text { optimization [101] } \\
\text { Enhanced colliding bodies } \\
\text { optimization [102] } \\
\text { Vibrating partial systems } \\
{[103]}\end{array}$ \\
\hline [96] & Rempling et al. & $\begin{array}{l}\text { Twin } \\
\text { girders }\end{array}$ & $\begin{array}{c}\text { Set-based parametric design } \\
{[97,98]} \\
\text { Set-based design }[97,98]\end{array}$ \\
\hline [93] & Pedro et al. & $\begin{array}{l}\text { Twin } \\
\text { girders }\end{array}$ & $\begin{array}{c}\text { Backtracking search } \\
\text { algorithm [104] } \\
\text { Firefly algorithm [105] } \\
\text { Genetic algorithm [106] } \\
\text { Imperialist competitive } \\
\text { algorithm [107] } \\
\text { Search group algorithm }\end{array}$ \\
\hline [99] & Kaveh et al. & $\begin{array}{l}\text { Box } \\
\text { girder }\end{array}$ & $\begin{array}{c}\text { Cuckoo search [109] } \\
\text { Harmony search [110] } \\
\text { Particle swarm optimization } \\
{[111]}\end{array}$ \\
\hline [94] & Lv et al. & $\begin{array}{l}\text { Plate } \\
\text { girder } \\
\text { Twin } \\
\text { girders }\end{array}$ & Matlab fmincon function \\
\hline [87] & $\begin{array}{l}\text { Briseghella } \\
\text { et al. }\end{array}$ & $\begin{array}{l}\text { Box } \\
\text { girder }\end{array}$ & $\begin{array}{c}\text { Ansys optimization tool } \\
\text { Topological optimization } \\
\text { [88-92] }\end{array}$ \\
\hline [9] & Musa and Diaz & $\begin{array}{l}\text { Box } \\
\text { girder }\end{array}$ & Excel solver \\
\hline
\end{tabular}

algorithms to the problems. There are no studies related to the knowledge of the algorithms in a more scientific way in the field of bridge optimization. Sörensen and Arnold [115] expose this phenomenon in his work and indicate that the trend to be taken is towards the understanding of the behavior of algorithms. The application of optimization algorithms in the field of structures and especially in the field of SCCBs is quite recent, and therefore further studies of different optimization methods is needed to have the possibility to compare. However, the study of how these techniques work and why some are better than others for this field of study should not be left aside.

3.4. Construction Process. The construction process of the SCCB is unique because the construction has a differentiation between the steel and concrete parts of the structure. The most common process is to build and place the steel part first using support systems to reduce the deflections of the steel part of the bridge. Then, the concrete slab formwork and the reinforcement are placed and the concrete is poured. This unique procedure gives the structure a characteristic behavior and researchers are currently developing and studying different construction processes for SCCBs [116-121]. The construction processes can be summarized as continuous precast girder bridges, incremental launching, span-by-span construction, and cantilever construction [122]. 
Here, we review the effects of the construction processes. Marí et al. studied the effects of construction process and slab prestressing on the serviceability behavior using a finite element model of one dimension [122], with a $14 \%$ increase in negative bending zones and a reduction of $50 \%$ in positive bending reported. Jung et al. [123] studied the behavior of a prestressed concrete box girder bridge with corrugated steel webs built by incremental launching. The results of the study conclude that this type of structural cross section allows the maximum span-to-depth ratio due to the self-weight reduction of the structure to be extended compared with a prestressed concrete box girder. Other authors have studied the precast construction of bridges in Europe and America [124]. They state that the construction of prefabricated bridges accelerates the construction of bridges and that the possibility of doing so with steel-concrete bridges is a good solution for the use of the material. This also occurs because such precast structures usually work in an isostatic way and therefore the upper concrete slab is compressed and the steel section is pulled. Another possibility is the use of removable prefabricated elements, allowing for connection of the precast concrete slabs with the steel beams, as in the study by Valipour et al. [125]. This study reveals that good results are obtained in the construction process in terms of ductility and strength using prefabricated elements.

In this field, the literature on SCCBs is scarce, so a detailed study is needed of their structural behavior with different construction methods. In addition, there are new methods being used to build mixed bridges that differ from the traditional ones. In addition, it is important to consider the new construction procedures as a further boundary condition for the models and work to find optimal solutions.

3.5. Maintenance and Repair. To reach a sustainable design, a complete study of all the stages of the service life of the bridge is required. Service life is a concept that allows designers and engineers to define the period of time that is considered to use the infrastructure. However, maintenance activities are necessary to keep the structure in a state that allows it to be used in a safe way. These activities can be preventive when related with the design of infrastructures preventing the possibility of damage [126] or corrective, with a repair approach. Focusing on the search in SCCBs, two main trends have been established: repair and renovation $[127,128]$ and the evaluation of bridge conditions [129-131].

In contrast, Albrecht and Lenwari propose three methods of fatigue damage repair [127]. The method that gives better results is to tension a steel wire in the low part of the steel section to compress the section, so that when loads are applied, the section will always be compressed. This gives a fatigue resistance higher than the one imposed by the AASTHO. Sugimoto et al. [128] proposed the reinforcement of steel railway bridges by placing a concrete slab on the top of the steel beams, transforming the steel bridge in a composite one, taking advantage of the composite action between steel and concrete, and improving the behavior against deflections. Alternatively, the authors have proposed different methods to assess bridge conditions, giving stakeholders infrastructure management data to make decisions regarding the maintenance of the bridge. Gheitasi and Harris [129], using a finite element model, assess the composite action that is still working in bridges with damage in the concrete slabs; this method allows us to evaluate if the structure needs maintenance or, on the contrary, it still has sufficient resistance capacity. In other studies, the authors proposed a decision-making method according to the data obtained by instrumented bridges that have corrosion damage on the steel beams [130]. The numerical model proposed by the author is capable of assessing the maintenance needs of the bridge by the infrastructure manager. Moreover, Matos et al. [131] proposed a model that is capable of introducing data from the bridge condition and uses Bayesian inference $[132,133]$ to reduce the uncertainty of model parameters, allowing stakeholders to take better decisions according to maintenance.

3.6. Life Cycle Assessment. Bridges have an associated impact during all phases of their life cycle. Therefore, researchers have searched for different ways to evaluate the impact of bridges in an objective way. Widman [134] applied the environmental priority strategies in product design (EPS), the environmental theme method (ETM), and the ecoscarcity method (EM) to assess the life cycle of a box girder SCCB. This evaluation resulted in a low maintenance impact of the bridge. The author states that the maintenance phase is very small and, therefore, it is not necessary to protect the structures, it is better to repair it. ISO 14040:2006 [135] defines the methodology to assess the life cycle of bridges for the first time; in this way, a framework is generated that allows researchers to have a guide for their studies. Gervasio and da Silva compared concrete with composite bridge solutions, analyzing the cost and the environmental impact, with the results showing that SCCBs have a higher cost but a low environmental impact [7]. Du and Karoumi [136] state that SCCBs are better from the point of view of the environmental impact due to the possibility of materializing slender sections and the higher capability to recycle of structural steel. The steel recycling rate for structural steel is $98 \%$ [137], which allows us to reduce the impact of SCCBs. In other researches, the authors have done a literary review of the LCA methods and software and implemented new LCA methods to reach the impact evaluations of SCCB railway bridges [138] and short span bridges [139].

As seen in Table 3, the studies carried out for the LCA of SCCBs have been focused on the economic and environmental pillars. For SCCBs, there exists a knowledge gap in the approach social of LCA. Furthermore, researchers have considered a cradle to grave approach. It is necessary to carry out studies with a broader vision to take into account the entire life cycle process, including the phases of dismantling and demolition of the structure and the recycling and reuse of materials.

3.7. Multi-Criteria Decision-Making. Decision-making is a process that allows solutions to be obtained that satisfy different objectives. This process can be carried out in many ways. Hwang and Yoon [142] classified the multi-criteria 
TABLE 3: Summary of SCCB LCA publications.

\begin{tabular}{|c|c|c|c|c|c|c|}
\hline Ref. & Year & Author & Structural type & Pillar & Method & Approach \\
\hline$[134]$ & 1998 & Widman & Box girder & Environmental & $\begin{array}{l}\text { EPS } \\
\text { ETM } \\
\text { EM }\end{array}$ & Cradle to grave \\
\hline [7] & 2008 & Gervasio and Da Silva & Twin girders & $\begin{array}{l}\text { Environmental } \\
\text { Economic }\end{array}$ & Lippiatt [140] & Cradle to grave \\
\hline $\begin{array}{l}{[136]} \\
{[85]} \\
{[139]}\end{array}$ & $\begin{array}{l}2013 \\
2017 \\
2019\end{array}$ & $\begin{array}{l}\text { Du and Karoumi } \\
\text { Batikha et al. } \\
\text { Milani and Kripka }\end{array}$ & $\begin{array}{l}\text { Twin girders } \\
\text { Twin girders } \\
\text { Plate girder }\end{array}$ & $\begin{array}{l}\text { Environmental } \\
\text { Economic } \\
\text { Environmental }\end{array}$ & $\begin{array}{c}\operatorname{ReCiPe}[141] \\
\text { Cost of materials and maintenance } \\
\operatorname{ReCiPe}[141]\end{array}$ & $\begin{array}{l}\text { Cradle to grave } \\
\text { Cradle to grave } \\
\text { Cradle to gate }\end{array}$ \\
\hline
\end{tabular}

decision-making processes into multi-attribute decisionmaking (MADM) and multi-objective decision-making. MADMs are used to decide on a discrete number of solutions which usually occurs in bridge design and more specifically at SCCBs.

Penadés-Plà et al. carried out a review of MCDM methods applied to bridges [11], but in SCCBs, these methods have not been extensively applied. Only two publications have been found related with that field. The first applies SCORE [143] and PANTURA [144] methods to choose the best alternative between concrete and composite I girder bridges [145]. In the other study, the method AHP [146] and Vikor [147] have been applied to short span bridges. In this second study, the results obtained gives as the most suitable solutions for the two methods the steel-concrete composite one. Furthermore, authors state that the application of MCDM in short span bridges can provide good design for small-span bridges to fulfil the needs of connection between areas in undeveloped countries [139].

According to the small number of well-founded investigations related to this research topic; it can be said that there is a lack of knowledge in this field. This must be completed with future studies that take into account the MCDM methodologies in each of the phases of the SCCB design cycle, introducing uncertainty and robustness in the decision-making process [148, 149].

\section{Discussion}

Most of the studies focus on preliminary design and structure behavior as these represent $66 \%$ of the total with 55 articles. Inside this category, three main trends have been found: bridge design (18\%), behavior (42\%), and calculation methods (13\%). The bridge design studies have been focused on the definition of the transverse section of bridges and the connection between the steel and concrete parts of the structures. In the behavior approach, a lack of research is observed in accidental actions, like fire and blasting loads, compared with other topics considered by authors, such as seism and fatigue behavior. In addition, other works have focused on the new calculation method considering sensitivity or reliability and carrying out statistical methods applied to the design of the structure.

Optimization research, which means the $13 \%$ of the total with 11 articles, has focused on cost optimization. There is a lack of knowledge in applying multi-criteria optimization methods and considering other criteria for the optimization, such as environmental or social. Furthermore, the optimization is only focused on the application of different algorithms to take results; however, the authors are not considering the study of the behavior of algorithms in structural optimization. There is a lack of knowledge according to the search for causes and reasons why some heuristics work better than others. Related with that field, the authors do not emphasize in the construction process, which is decisive in many cases. This may be due to the lack of study of the behavior of SCCBs in the construction processes with only a $5 \%$ of papers of the total considered.

Once the final design is defined, the structure has a defined service life. To reach this, it is important to define the maintenance periods and, if it is necessary, the repairs. There are few studies focused on the repair and maintenance of SCCBs, representing the $6 \%$ of the total. Work in this field focuses on evaluating the condition of bridges and defining the repairs to be carried out. There is a lack of knowledge in the preventive maintenance of this type of structures. There are currently techniques for evaluating the impact of these actions and methods for making decisions regarding maintenance, repair, and demolition. These methods are LCA and MCDM.

LCA and MCDM studies, which represent the $8 \%$ and $2 \%$, respectively, are closely related in the studies included in this review. These methods are used to choose the best alternative, comparing between concrete, steel, composite, and timber bridges. These methods always give SCCBs as a good alternative compared with concrete. Because of this, it is important not only to apply these methods for the type of bridge selection but also to use these methods to assess the needs of the bridges built, in maintenance, repair, or demolition according to different criteria.

To identify the relation between the research fields, the sustainable design phases, and the structural type of the cross sections of bridges, a statistical analysis has been carried out. The method used to study the relation between that variables have been the simple correspondence analysis [150]. To use this method, every publication has to be classified according to the research field, the design phase, and the structural type considered in every study. Once the classification is completed, the frequency of each combination of variables has to be obtained. The method uses the chi-squared distance to give as a result the relation between every categories of each variable. IBM SPSS Statistics for Windows, Version 25.0 [10], software have been used to carry out the statistical analysis. For clearer results, the variables have been compared in pairs, obtaining the results shown in Figures 5 and 6. 


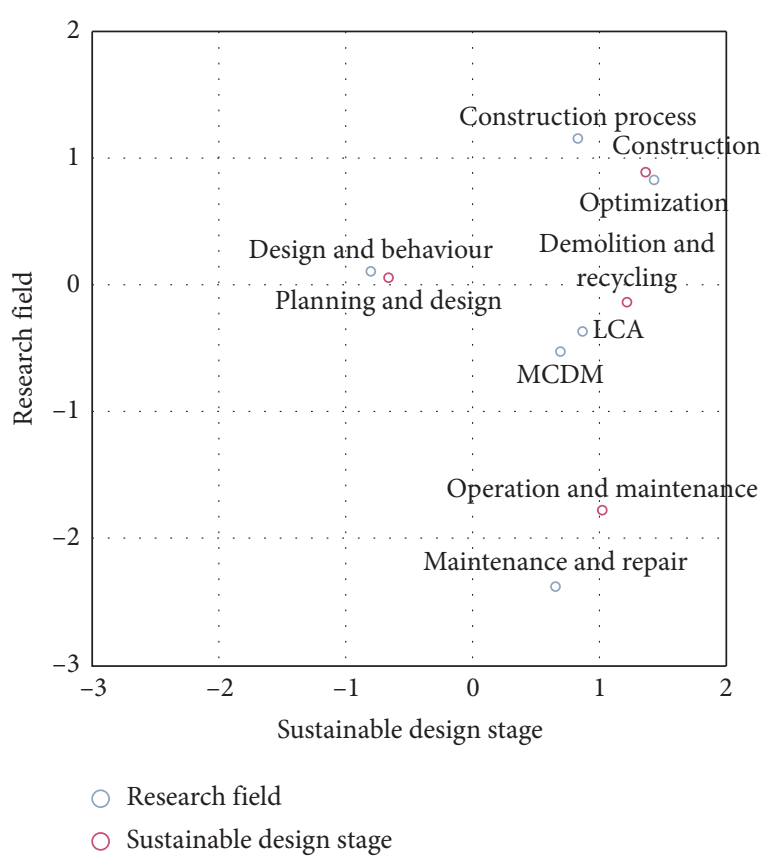

FIGURE 5: Simple correspondence analysis for research field and sustainable design stages.

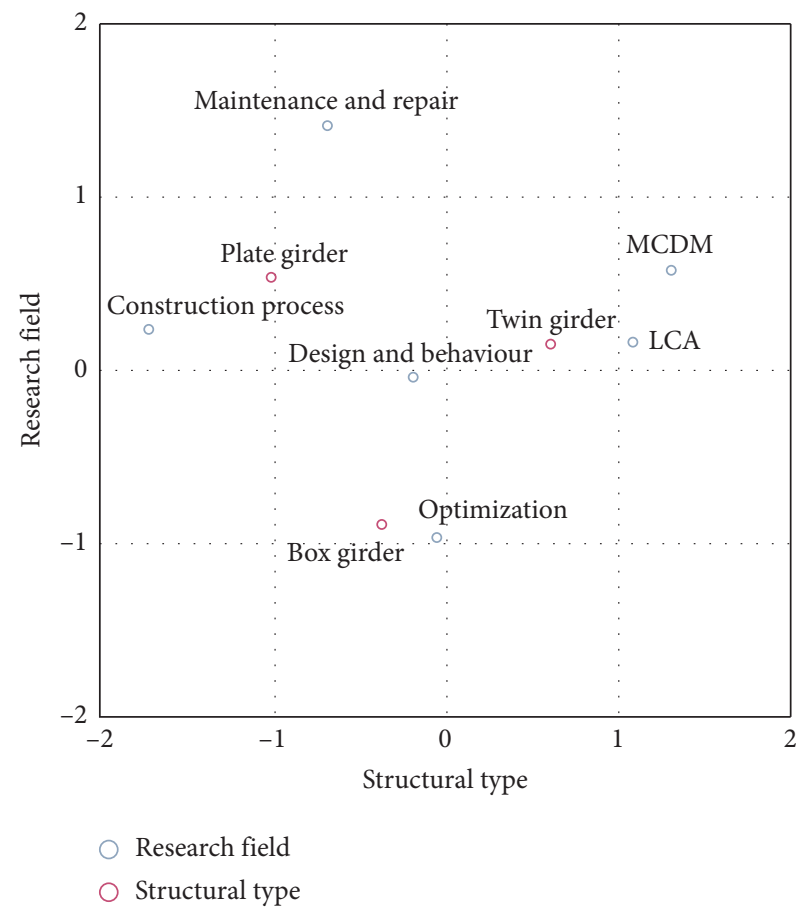

FIGURE 6: Simple correspondence analysis for research field and structural type.

In Figure 5, the results of the simple correspondence analysis are shown for the Research field and Sustainable design stage variables. The graphic shows a clear relationship between Design and Behavior with Planning and Design stages and between Construction and Optimization. These results are logical because the Planning and Design stage is related with obtaining a first design that has to be improved at later stages. To reach that first design, it is necessary to consider the structural behavior of the SCCB. To obtain the final design to build the bridge, the construction process of the bridge and the optimization procedure must be considered. These concepts are in line with the graph, but it is observed that, in the studies considered in this review, the construction design is focused more on optimization than on the construction process. This result shows a lack of consideration of the construction process in the optimization. Furthermore, it can be seen that the LCA and MCDM are quite linked to the Demolition and Recycle design stage. This is because a large part of these studies focus on making decisions between maintenance and repair of SCCBs or demolition. This is an important topic that should be developed in subsequent studies due to the lack of studies related to these topics for SCCBs.

Figure 6 shows the relation between the research fields and the structural type of the transverse section.

Articles that consider the box girder sections for the studies are 28. Otherwise, plate girder and twin girder sections are considered in 23 and 64 of the articles in this paper, respectively. There is a relation between the box girder cross section and the Optimization field, while the twin girders section is more related with the $L C A$. The distance between the box girder section with other research field shows a need to carry out studies related with the construction process, the maintenance and repair, and the study of the design and behavior considering MCDM and LCA. The results of the analysis between the field of knowledge and the structural type of the cross section, in general, do not show a clear relation between them. This is a sign of a lack of studies in most fields, which is an opportunity for researchers to develop these topics in greater depth.

The statistical analysis accomplished in this review shows the relation between the fields of knowledge with every design phase. Based on the results obtained, it can be state that construction should be considered in optimization as a determining factor. The LCA and MCDM methods are related to maintenance and repair and demolition phases due to the need of decision-making and assessment methods to ease the decision of stakeholders in infrastructure management. The studies have not a clear relation between the research fields and the cross section type of SCCBs. A larger study should be done to complete the lack of knowledge identified in this work.

\section{Conclusions}

This review has focused on a design approach for steelconcrete composite bridges. Four design stages have been considered, and the research fields related to that phases have been reviewed. These research fields are Design And Behavior (66\%), Optimization (13\%), Construction Process (5\%), Maintenance and Repair (6\%), Life Cycle Assessment (8\%), and Multi-Criteria Decision-Making (2\%). To improve the literature review, a statistical analysis has been carried out to look for relations between fields of study, design stages, and bridge cross section types. 
Most of the studies focus on preliminary design and structure behavior. The bridge design studies have been focused on the definition of the transverse section of bridges and the connection between the steel and concrete parts of the structures. It is observed a lack of research in the behavior of SCCBs summited to accidental actions. Furthermore, the trend of new calculation methods is related to adding sensitivity or reliability to the analysis. Optimization research has focused on cost optimization. There is lack of knowledge in applying multi-criteria optimization methods and considering other criteria for the optimization, such as environmental or social. This is far from the current trend of searching for sustainable solutions considering all the pillars of sustainability. The studies focused on the repair and maintenance to evaluate the condition of bridges and define the repairs to be carried out. There is a lack of knowledge in the preventive maintenance of these types of structures and LCA and MCDM methods for maintenance management. These methods are applied only to compare between types of bridge. It is observed that the results of these methods give SCCBs as a good alternative from an environmental point of view.

The SCCB literature review carried out shows the gaps in the fields related with bridge design. This work can be a useful tool for researchers to focus their analysis in those gaps. In this way, research related to the design of steelconcrete composite bridges will be able to focus on those topics that have not yet been dealt with in depth.

\section{Data Availability}

The raw/processed data required to reproduce these findings cannot be shared at this time as the data also form part of an ongoing study.

\section{Conflicts of Interest}

The authors declare that there are no conflicts of interest regarding the publication of this article.

\section{Acknowledgments}

This study was funded by the Spanish Ministry of Economy and Competitiveness, along with FEDER funding (DIMALIFE Project BIA2017-85098-R).

\section{References}

[1] D. Collings, Steel-Concrete Composite Bridges, Thomas Telford, London, UK, 2005.

[2] R. A. Smith, J. R. Kersey, and P. J. Griffiths, "The construction industry mass balance: resource use, wastes and emissions," Construction, vol. 4, p. 680, 2002.

[3] J. H. Spangenberg, A. Fuad-Luke, and K. Blincoe, "Design for sustainability ( $\mathrm{dfs}$ ): the interface of sustainable production and consumption," Journal of Cleaner Production, vol. 18, no. 15, pp. 1485-1493, 2010.

[4] World Commission on Environment and Development, Our Common Future, World Commission on Environment and Development, New York, NY, USA, 1987.
[5] United Nations, The Future We Want, United Nations, New York, NY, USA, 2012.

[6] C. W. De Jong, Ten Principles for Good Design: Dieter Rams: The Jorrit Maan Collection, Prestel Publishing, Munich, Germany, 2017.

[7] H. Gervásio and L. S. O. E. Da Silva, "Comparative life-cycle analysis of steel-concrete composite bridges," Structure and Infrastructure Engineering, vol. 4, no. 4, pp. 251-269, 2008.

[8] J. Bernabeu Larena, Evolución Tipológica y Estética de los Puentes Mixtos en Europa, Caminos Canales y Puertos (UPM), Madrid, Spain, 2004.

[9] Y. I. Musa and M. A. Diaz, "Design optimization of composite steel box girder in flexure," Practice Periodical on Structural Design and Construction, vol. 12, no. 3, pp. 146152, 2007.

[10] IBM, IBM SPSS Statistics for Windows, IBM, Armonk, NY, USA, 2017.

[11] V. Penadés-Plà, T. García-Segura, J. Martí, and V. Yepes, “A review of multi-criteria decision-making methods applied to the sustainable bridge design," Sustainability, vol. 8, no. 12, p. 1295, 2016.

[12] V. Belton and T. J. Stewart, Multiple Criteria Decision Analysis, Springer, New York City, NY, USA, 2002.

[13] I. Vayas and A. Iliopoulos, Design of Steel-Concrete Composite Bridges to Eurocodes, CRC Press, Boca Raton, FL, USA, 2013.

[14] European Committee for Standardization, Eurocode 4: Design of Composite Steel and Concrete Structures-Part 2: General Rules and Rules for Bridges, European Committee for Standardization, Brussels, Belgium, 2005.

[15] S.-I. Nakamura, Y. Momiyama, T. Hosaka, and K. Homma, "New technologies of steel/concrete composite bridges," Journal of Constructional Steel Research, vol. 58, no. 1, pp. 99-130, 2002.

[16] H.-Y. Kim and Y.-J. Jeong, "Steel-concrete composite bridge deck slab with profiled sheeting," Journal of Constructional Steel Research, vol. 65, no. 8-9, pp. 1751-1762, 2009.

[17] Y. Xie, H. Yang, Z. Zuo, and Z. Gao, "Optimal depth-to-span ratio for composite rigid-frame bridges," Practice Periodical on Structural Design and Construction, vol. 24, no. 2, pp. 1-8, 2019.

[18] H.-Y. Kim and Y.-J. Jeong, "Ultimate strength of a steelconcrete composite bridge deck slab with profiled sheeting," Engineering Structures, vol. 32, no. 2, pp. 534-546, 2010.

[19] A. Vasseghi, "Improving strength and ductility of continuous composite plate girder bridges," Journal of Constructional Steel Research, vol. 65, no. 2, pp. 479-488, 2009.

[20] X. Shao, D. Yi, Z. Huang, H. Zhao, B. Chen, and M. Liu, "Basic performance of the composite deck system composed of orthotropic steel deck and ultrathin RPC layer," Journal of Bridge Engineering, vol. 18, no. 5, pp. 417-428, 2013.

[21] L. Wu, J. Nie, J. Lu, J. Fan, and C. S. Cai, "A new type of steelconcrete composite channel girder and its preliminary experimental study," Journal of Constructional Steel Research, vol. 85, pp. 163-177, 2013.

[22] J. G. Nie, Y. J. Zhu, M. X. Tao, C. R. Guo, and Y. X. Li, "Optimized prestressed continuous composite girder bridges with corrugated steel webs," Journal of Bridge Engineering, vol. 22, no. 2, pp. 1-17, 2017.

[23] P. M. Esteves, J. F. Almeida, and J. J. Oliveira Pedro, "Steelconcrete hybrid bridge decks: rational design models for connection regions," Proceedings of the Institution of Civil Engineers - Bridge Engineering, vol. 171, no. 4, pp. 252-266, 2018. 
[24] L. Peng-Zhen, C. Lin-Feng, L. Yang, L. Zheng-Lun, and S. Hua, "Study on mechanical behavior of negative bending region based design of composite bridge deck," International Journal of Civil Engineering, vol. 16, no. 5, pp. 489-497, 2018.

[25] Y. Xie, H. Yang, Z. Zuo, T. L. Sirotiak, and M. Yang, "Optimal steel section length of the composite rigid-frame bridge," Practice Periodical on Structural Design and Construction, vol. 23, no. 3, 2018.

[26] V. Kodur, E. Aziz, and M. Dwaikat, "Evaluating fire resistance of steel girders in bridges," Journal of Bridge Engineering, vol. 18, no. 7, pp. 633-643, 2013.

[27] J. Alos-Moya, I. Paya-Zaforteza, M. E. M. Garlock, E. LomaOssorio, D. Schiffner, and A. Hospitaler, "Analysis of a bridge failure due to fire using computational fluid dynamics and finite element models," Engineering Structures, vol. 68, pp. 96-110, 2014.

[28] E. M. Aziz, V. K. Kodur, J. D. Glassman, and M. E. Moreyra Garlock, "Behavior of steel bridge girders under fire conditions," Journal of Constructional Steel Research, vol. 106, pp. 11-22, 2015.

[29] J. Alos-Moya, I. Paya-Zaforteza, A. Hospitaler, and P. Rinaudo, "Valencia bridge fire tests: experimental study of a composite bridge under fire," Journal of Constructional Steel Research, vol. 138, pp. 538-554, 2017.

[30] J. Hu, A. Usmani, A. Sanad, and R. Carvel, "Fire resistance of composite steel \& concrete highway bridges," Journal of Constructional Steel Research, vol. 148, pp. 707-719, 2018.

[31] A. Astaneh-Asl and R. G. Black, "Seismic and structural engineering of a curved cable-stayed bridge," Journal of Bridge Engineering, vol. 6, no. 6, pp. 439-450, 2001.

[32] S. Maleki, "Seismic energy dissipation with shear connectors for bridges," Engineering Structures, vol. 28, no. 1, pp. 134-142, 2006.

[33] E. Tubaldi, M. Barbato, and A. Dall'Asta, “Transverse seismic response of continuous steel-concrete composite bridges exhibiting dual load path," Earthquakes and Structures, vol. 1, no. 1, pp. 21-41, 2010.

[34] J. Seo and D. G. Linzell, "Horizontally curved steel bridge seismic vulnerability assessment," Engineering Structures, vol. 34, pp. 21-32, 2012.

[35] E. Tubaldi, M. Barbato, M. Asce, and A. Dall'Asta, "Influence of model parameter uncertainty on seismic transverse response and vulnerability of steel-concrete composite bridges with dual load path," Journal of Structural Engineering, vol. 138, no. 8, pp. 363-374, 2012.

[36] E. Tubaldi, A. Dall'Asta, and L. Dezi, "Reduced formulation for post-elastic seismic response of dual load path bridges," Engineering Structures, vol. 51, pp. 178-187, 2013.

[37] G.-F. Du, X.-M. Bie, Z. Li, and W.-Q. Guan, "Study on constitutive model of shear performance in panel zone of connections composed of CFSSTCs and steel-concrete composite beams with external diaphragms," Engineering Structures, vol. 155, pp. 178-191, 2018.

[38] S. Carbonari, F. Gara, A. Dall'Asta, and L. Dezi, "Shear connection local problems in the seismic design of steelconcrete composite decks," Lecture Notes in Civil Engineering, vol. 10, pp. 341-354, 2018.

[39] G. Abbiati, E. Cazzador, S. Alessandri, O. S. Bursi, F. Paolacci, and S. De Santis, "Experimental characterization and component-based modeling of deck-to-pier connections for composite bridges," Journal of Constructional Steel Research, vol. 150, pp. 31-50, 2018.

[40] J.-H. Ahn, C. Sim, Y.-J. Jeong, and S.-H. Kim, "Fatigue behavior and statistical evaluation of the stress category for a steel-concrete composite bridge deck," Journal of Constructional Steel Research, vol. 65, no. 2, pp. 373-385, 2009.

[41] F. N. Leitão, J. G. S. Da Silva, P. C. G. Da Vellasco, S. A. L. De Andrade, and L. R. O. De Lima, "Composite (steel-concrete) highway bridge fatigue assessment," Journal of Constructional Steel Research, vol. 67, no. 1, pp. 14-24, 2011.

[42] J. Xu, H. Sun, S. Cai, W. Sun, and B. Zhang, "Fatigue testing and analysis of i-girders with trapezoidal corrugated webs," Engineering Structures, vol. 196, Article ID 109344, 2019.

[43] L. Deng, W. Yan, and S. Li, "Computer modeling and weight limit analysis for bridge structure fatigue using opensees," Journal of Bridge Engineering, vol. 24, no. 8, 2019.

[44] L. Deng and W. Yan, "Vehicle weight limits and overload permit checking considering the cumulative fatigue damage of bridges," Journal of Bridge Engineering, vol. 23, no. 7, 2018.

[45] S. Zhang, X. Shao, J. Cao, J. Cui, J. Hu, and L. Deng, "Fatigue performance of a lightweight composite bridge deck with open ribs," Journal of Bridge Engineering, vol. 21, no. 7, 2016.

[46] C. Xu, Q. Su, and K. Sugiura, "Mechanism study on the low cycle fatigue behavior of group studs shear connectors in steel-concrete composite bridges," Journal of Constructional Steel Research, vol. 138, pp. 196-207, 2017.

[47] X. Wei, L. Xiao, and S. Pei, "Experiment study on fatigue performance of perforated shear connectors," International Journal of Steel Structures, vol. 17, no. 3, pp. 957-967, 2017.

[48] G. Alencar, A. M. P. De Jesus, R. A. B. Calçada, and J. G. S. D. Silva, "Fatigue life evaluation of a composite steelconcrete roadway bridge through the hot-spot stress method considering progressive pavement deterioration," Engineering Structures, vol. 166, pp. 46-61, 2018.

[49] B. Ovuob and G. S. Prinz, "Investigation of residual fatigue life in shear studs of existing composite bridge girders following decades of traffic loading," Engineering Structures, vol. 161, pp. 134-145, 2018.

[50] X. Chen, S. Kunitomo, and S. Qingtian, "Fatigue behavior of the group stud shear connectors in steel-concrete composite bridges," Journal of Bridge Engineering, vol. 23, no. 8, Article ID 4018055, 2018.

[51] S. Yuan, J. Dong, Q. Wang, and J. Y. Ooi, "Retracted: fatigue property study and life assessment of composite girders with two corrugated steel webs," Journal of Constructional Steel Research, vol. 141, pp. 287-295, 2018.

[52] Z. Zhu, T. Yuan, Z. Xiang, Y. Huang, Y. E. Zhou, and $\mathrm{X}$. Shao, "Behavior and fatigue performance of details in an orthotropic steel bridge with UHPC-deck plate composite system under in-service traffic flows," Journal of Bridge Engineering, vol. 23, no. 3, 2018.

[53] M. Arici, M. F. Granata, and M. Oliva, "Influence of secondary torsion on curved steel girder bridges with box and i-girder cross-sections," KSCE Journal of Civil Engineering, vol. 19, no. 7, pp. 2157-2171, 2015.

[54] A. Camara and A. M. Ruiz-Teran, "Multi-mode traffic-induced vibrations in composite ladder-deck bridges under heavy moving vehicles," Journal of Sound and Vibration, vol. 355, pp. 264-283, 2015.

[55] F. Sadeghi, A. Kueh, A. Bagheri Fard, and N. Aghili, "Vibration characteristics of composite footbridges under various human running loads," ISRN Civil Engineering, vol. 2013, Article ID 817384, 8 pages, 2013.

[56] M. Podworna and M. Klasztorny, "Vertical vibrations of composite bridge/track structure/high-speed train systems. Part 2: physical and mathematical modelling," Bulletin of the 
Polish Academy of Sciences: Technical Sciences, vol. 62, no. 1, pp. 181-196, 2014.

[57] M. Podworna and M. Klasztorny, "Vertical vibrations of composite bridge/track structure/high-speed train systems. Part 1: series-of-types of steel-concrete bridges," Bulletin of the Polish Academy of Sciences: Technical Sciences, vol. 62, no. 1, pp. 165-179, 2014.

[58] M. Podworna and M. Klasztorny, "Vertical vibrations of composite bridge/track structure/high-speed train systems. Part 3: deterministic and random vibrations of exemplary system," Bulletin of the Polish Academy of Sciences Technical Sciences, vol. 62, no. 2, pp. 305-320, 2014.

[59] F. Sadeghi and A. B. Hong Kueh, "Serviceability assessment of composite footbridge under human walking and running loads," Jurnal Teknologi, vol. 74, no. 4, pp. 73-77, 2015.

[60] Y. Li and S. He, "Research of steel-concrete composite bridge under blasting loads," Advances in Civil Engineering, vol. 2018, Article ID 5748278, 9 pages, 2018.

[61] M. Yarnold, T. Golecki, and J. Weidner, "Identification of composite action through truck load testing," Frontiers in Built Environment, vol. 4, 2018.

[62] L. Zhengyuan, M. Xiaowei, F. Jiansheng, and N. Xin, "Overhanging tests of steel-concrete composite girders with different connectors," Journal of Bridge Engineering, vol. 24, no. 11, Article ID 4019098, 2019.

[63] F. A. Sofi and J. S. Steelman, "Nonlinear flexural distribution behavior and ultimate system capacity of skewed steel girder bridges," Engineering Structures, vol. 197, Article ID 109392, 2019.

[64] A. Gheitasi and D. K. Harris, "Overload flexural distribution behavior of composite steel girder bridges," Journal of Bridge Engineering, vol. 20, no. 5, 2015.

[65] A. Gheitasi and D. K. Harris, "Failure characteristics and ultimate load-carrying capacity of redundant composite steel girder bridges: case study," Journal of Bridge Engineering, vol. 20 , no. 3, 2015.

[66] V. Saraf and A. S. Nowak, "Proof load testing of deteriorated steel girder bridges," Journal of Bridge Engineering, vol. 3, no. 2, pp. 82-89, 1998.

[67] S. Qingtian, D. Changyuan, and X. Chen, "Full-scale experimental study on the negative flexural behavior of orthotropic steel-concrete composite bridge deck," Journal of Bridge Engineering, vol. 23, no. 12, Article ID 4018097, 2018.

[68] A. Zona, M. Barbato, A. Dall'Asta, and L. Dezi, "Probabilistic analysis for design assessment of continuous steel-concrete composite girders," Journal of Constructional Steel Research, vol. 66, no. 7, pp. 897-905, 2010.

[69] F. Gara, G. Ranzi, and G. Leoni, "Simplified method of analysis accounting for shear-lag effects in composite bridge decks," Journal of Constructional Steel Research, vol. 67, no. 10, pp. 1684-1697, 2011.

[70] J. G. Nie and L. Zhu, "Beam-truss model of steel-concrete composite box-girder bridges," Journal of Bridge Engineering, vol. 19, no. 7, 2014.

[71] Y. Deng, B. M. Phares, and O. W. Steffens, "Experimental and numerical evaluation of a folded plate girder system for short-span bridges-a case study," Engineering Structures, vol. 113, pp. 26-40, 2016.

[72] B. Jia, X. Yu, Q. Yan, and Z. Yang, "Study on the system reliability of steel-concrete composite beam cable-stayed bridge," The Open Civil Engineering Journal, vol. 10, no. 1, pp. 418-432, 2016.

[73] T. Tong, Q. Yu, and Q. Su, "Coupled effects of concrete shrinkage, creep, and cracking on the performance of postconnected prestressed steel-concrete composite girders," Journal of Bridge Engineering, vol. 23, no. 3, 2018.

[74] D. K. Harris, "Assessment of flexural lateral load distribution methodologies for stringer bridges," Engineering Structures, vol. 32, no. 11, pp. 3443-3451, 2010.

[75] D. K. Harris and A. Gheitasi, "Implementation of an energybased stiffened plate formulation for lateral load distribution characteristics of girder-type bridges," Engineering Structures, vol. 54, pp. 168-179, 2013.

[76] R. E. Melchers, Structural Reliability: Analysis and Prediction, John Wiley \& Sons, Chichester, UK, 2002.

[77] M. Kleiber, Parameter Sensitivity in Nonlinear Mechanics: Theory and Finite Element Computations, John Wiley \& Sons, Chichester, UK, 1997.

[78] Y. Zhang and A. Der Kiureghian, "Dynamic response sensitivity of inelastic structures," Computer Methods in Applied Mechanics and Engineering, vol. 108, no. 1-2, pp. 23-36, 1993.

[79] J. P. Conte, P. K. Vijalapura, and M. Meghella, "Consistent finite-element response sensitivity analysis," Journal of Engineering Mechanics, vol. 129, no. 12, pp. 1380-1393, 2003.

[80] J. Conte, M. Barbato, and Q. Gu, "Finite element response sensitivity, probabilistic response and reliability analyses," 2009.

[81] J. V. Martí, T. García-Segura, and V. Yepes, "Structural design of precast-prestressed concrete u-beam road bridges based on embodied energy," Journal of Cleaner Production, vol. 120, pp. 231-240, 2016.

[82] V. Yepes, J. V. Martí, T. García-Segura, and F. GonzálezVidosa, "Heuristics in optimal detailed design of precast road bridges," Archives of Civil and Mechanical Engineering, vol. 17, no. 4, pp. 738-749, 2017.

[83] V. Penadés-Plà, T. García-Segura, J. Martí, and V. Yepes, "An optimization-LCA of a prestressed concrete precast bridge," Sustainability, vol. 10, no. 3, p. 685, 2018.

[84] V. Yepes, M. Dasí-Gil, D. Martínez-Muñoz, V. J. LópezDesfilis, and J. V. Martí, "Heuristic techniques for the design of steel-concrete composite pedestrian bridges," Applied Sciences, vol. 9, no. 16, p. 3253, 2019.

[85] M. Batikha, O. Al Ani, and T. Elhag, "The effect of span length and girder type on bridge costs," MATEC Web of Conferences, vol. 120, Article ID 08009, 2017.

[86] J. Surtees and D. Tordoff, "Optimum design of composite box girder bridge structures," Proceedings of the Institution of Civil Engineers, vol. 63, no. 1, pp. 181-198, 1977.

[87] B. Briseghella, L. Fenu, C. Lan, E. Mazzarolo, and T. Zordan, "Application of topological optimization to bridge design," Journal of Bridge Engineering, vol. 18, no. 8, pp. 790-800, 2013.

[88] M. P. Bendsøe, "Optimal shape design as a material distribution problem," Structural Optimization, vol. 1, no. 4, pp. 193-202, 1989.

[89] M. P. Bendsøe and N. Kikuchi, "Generating optimal topologies in structural design using a homogenization method," Computer Methods in Applied Mechanics and Engineering, vol. 71, no. 2, pp. 197-224, 1988.

[90] O. Sigmund, "A 99 line topology optimization code written in matlab," Structural and Multidisciplinary Optimization, vol. 21, no. 2, pp. 120-127, 2001.

[91] C. S. Edwards, H. A. Kim, and C. J. Budd, "An evaluative study on ESO and SIMP for optimising a cantilever tiebeam," Structural and Multidisciplinary Optimization, vol. 34, no. 5, pp. 403-414, 2007. 
[92] Y. M. Xie and G. P. Steven, "A simple evolutionary procedure for structural optimization," Computers \& Structures, vol. 49, no. 5, pp. 885-896, 1993.

[93] R. L. Pedro, J. Demarche, L. F. F. Miguel, and R. H. Lopez, "An efficient approach for the optimization of simply supported steel-concrete composite i-girder bridges," Advances in Engineering Software, vol. 112, pp. 31-45, 2017.

[94] N. Lv and L. Fan, "Optimization of quickly assembled steelconcrete composite bridge used in temporary," Modern Applied Science, vol. 8, no. 4, pp. 134-143, 2014

[95] A. Orcesi, C. Cremona, and B. Ta, "Optimization of design and life-cycle management for steel-concrete composite bridges," Structural Engineering International, vol. 28, no. 2, pp. 185-195, 2018.

[96] R. Rempling, A. Mathern, D. Tarazona Ramos, and S. Luis Fernández, "Automatic structural design by a set-based parametric design method," Automation in Construction, vol. 108, Article ID 102936, 2019.

[97] Y.-E. Nahm and H. Ishikawa, "A new 3D-CAD system for set-based parametric design," The International Journal of Advanced Manufacturing Technology, vol. 29, no. 1-2, pp. 137-150, 2006.

[98] A. Ward, J. K. Liker, J. J. Cristiano, and D. K. Sloan, "The second toyota paradox: how delaying decisions can make better cars faster," Long Range Planning, vol. 28, no. 4, p. 129, 1995.

[99] A. Kaveh, T. Bakhshpoori, and M. Barkhori, "Optimum design of multi-span composite box girder bridges using cuckoo search algorithm," Steel and Composite Structures, vol. 17, no. 5, pp. 703-717, 2014.

[100] A. Kaveh and M. M. M. Zarandi, "Optimal design of steelconcrete composite i-girder bridges using three meta-heuristic algorithms," Periodica Polytechnica Civil Engineering, vol. 63, no. 2, pp. 317-337, 2019.

[101] A. Kaveh and V. R. Mahdavi, "Colliding bodies optimization: a novel meta-heuristic method," Computers \& Structures, vol. 139, pp. 18-27, 2014.

[102] A. Kaveh and M. Ilchi Ghazaan, "Enhanced colliding bodies optimization for design problems with continuous and discrete variables," Advances in Engineering Software, vol. 77, pp. 66-75, 2014.

[103] A. Kaveh, A. Kaveh, and M. Ilchi Ghazaan, "A new metaheuristic algorithm: vibrating particles system," Scientia Iranica, vol. 24, no. 2, pp. 551-566, 2017.

[104] P. Civicioglu, "Backtracking search optimization algorithm for numerical optimization problems," Applied Mathematics and Computation, vol. 219, no. 15, pp. 8121-8144, 2013.

[105] X. S. Yang, "Firefly algorithm," in Engineering Optimization, pp. 221-230, Wiley, Hoboken, NJ, USA, 2010.

[106] J. H. Holland, Adaptation in Natural and Artificial Systems, MIT Press, Cambridge, MA, USA, 1975.

[107] E. Atashpaz-Gargari and C. Lucas, "Imperialist competitive algorithm: an algorithm for optimization inspired by imperialistic competition," in Proceedings of the 2007 IEEE Congress on Evolutionary Computation, pp. 4661-4667, Singapore, September 2007.

[108] M. S. Gonçalves, R. H. Lopez, and L. F. F. Miguel, "Search group algorithm: a new metaheuristic method for the optimization of truss structures," Computers \& Structures, vol. 153, pp. 165-184, 2015.

[109] X. Yang, Nature-Inspired Metaheuristic Algorithms, Luniver Press, London, UK, 2010.

[110] F. Glover and G. A. Kochenberger, Handbook of Metaheuristics, Springer, Berlin, Germany, 2003.
[111] J. Kennedy, R. C. Eberhart, and Y. B. T.-S. I. Shi, "Swarm Intelligence," in The Morgan Kaufmann Series In Artificial Intelligence, Morgan Kaufmann Publishers, Burlington, MA, USA, 2001.

[112] T. García-Segura, V. Penadés-Plà, and V. Yepes, "Sustainable bridge design by metamodel-assisted multi-objective optimization and decision-making under uncertainty," Journal of Cleaner Production, vol. 202, pp. 904-915, 2018.

[113] V. Yepes, T. García-Segura, and J. M. Moreno-Jiménez, “A cognitive approach for the multi-objective optimization of RC structural problems," Archives of Civil and Mechanical Engineering, vol. 15, no. 4, pp. 1024-1036, 2015.

[114] V. Penadés-Plà, T. García-Segura, and V. Yepes, "Accelerated optimization method for low-embodied energy concrete box-girder bridge design," Engineering Structures, vol. 179, pp. 556-565, 2019.

[115] K. Sörensen and F. Arnold, "What makes a VRP solution good? the generation of problem-specific knowledge for heuristics," Computers \& Operations Research, vol. 106, pp. 280-288, 2019.

[116] J. Martínez-Calzón and J. Ortiz-Herrera, Composite SteelConcrete Construction, Editorial Rueda, Madrid, Spain, 1978.

[117] J. Asencio, "The construction process of composite bridges. experiences of DyC: solutions and considerations," in Proceedings of the 2nd International Workshop on Composite Bridges, State of the Art on Technology and Analysis, pp. 565-567, New Orleans, LA, USA, August 1995.

[118] J. Strasky, "Segmentally erected structures," in Tendencies on Bridge Design, pp. 297-327, 2000.

[119] J. Martínez-Calzón, "Innovations on bridge construction. A general view of new execution methods of steel and concrete composite bridges," in Tendencies On Bridge Design, pp. $167-185,2000$.

[120] D. Poineau, J. Lacombe, and J. Berthellemy, Cracking Control in the Concrete Slab of the Nevers Composite Bridge. Composite Construction-Conventional and Innovative, pp. 199-204, International Association for Bridge and Structural Engineering, Zürich, Switzerland, 1997.

[121] J. M. Ducret, Etude du comportament Réel des Ponts Mixtes et Modélisation Pour le Dimensionnement, École Polytechnique Fédérale de Lausanne, Lausanne, Switzerland, 1997.

[122] A. Marí, E. Mirambell, and I. Estrada, "Effects of construction process and slab prestressing on the serviceability behaviour of composite bridges," Journal of Constructional Steel Research, vol. 59, no. 2, pp. 135-163, 2003.

[123] K. Jung, K. Kim, C. Sim, and J. J. Kim, "Verification of incremental launching construction safety for the ilsun bridge, the world's longest and widest prestressed concrete box girder with corrugated steel web section," Journal of Bridge Engineering, vol. 16, no. 3, pp. 453-460, 2011.

[124] R. Hällmark, H. White, and P. Collin, "Prefabricated bridge construction across Europe and America," Practice Periodical on Structural Design and Construction, vol. 17, no. 3, pp. 82-92, 2012.

[125] H. Valipour, A. Rajabi, S. J. Foster, and M. A. Bradford, "Arching behaviour of precast concrete slabs in a deconstructable composite bridge deck," Construction and Building Materials, vol. 87, pp. 67-77, 2015.

[126] I. J. Navarro, J. V. Martí, and V. Yepes, "Reliability-based maintenance optimization of corrosion preventive designs under a life cycle perspective," Environmental Impact Assessment Review, vol. 74, pp. 23-34, 2019. 
[127] P. Albrecht and A. Lenwari, "Fatigue strength of repaired prestressed composite beams," Journal of Bridge Engineering, vol. 13, no. 4, pp. 409-417, 2008.

[128] I. Sugimoto, Y. Yoshida, and A. Tanikaga, "Development of composite steel girder and concrete slab method for renovation of existing steel railway bridges," Quarterly Report of RTRI, vol. 54, no. 1, pp. 8-11, 2013.

[129] A. Gheitasi and D. K. Harris, "Performance assessment of steel-concrete composite bridges with subsurface deck deterioration," Structures, vol. 2, pp. 8-20, 2015.

[130] A. Gheitasi and D. K. Harris, "Redundancy and operational safety of composite stringer bridges with deteriorated girders," Journal of Performance of Constructed Facilities, vol. 30, no. 2, 2016.

[131] J. C. Matos, V. N. Moreira, I. B. Valente, P. J. S. Cruz, L. C. Neves, and N. Galvão, "Probabilistic-based assessment of existing steel-concrete composite bridges-application to sousa river bridge," Engineering Structures, vol. 181, pp. 95-110, 2019.

[132] J.-M. Bernardo, Bayesian Theory, John Wiley \& Sons, Chichester, UK, 2001.

[133] L. Jacinto, L. C. Neves, and L. O. Santos, "Bayesian assessment of an existing bridge: a case study," Structure and Infrastructure Engineering, vol. 12, no. 1, pp. 61-77, 2016.

[134] J. Widman, "Environmental impact assessment of steel bridges," Journal of Constructional Steel Research, vol. 46, no. 1-3, pp. 291-293, 1998.

[135] ISO, ISO 14040:2006-Environmental Management-Life Cycle Assessment-Principles and Framework, ISO, London, UK, 2006.

[136] G. Du and R. Karoumi, "Environmental life cycle assessment comparison between two bridge types: reinforced concrete bridge and steel composite bridge," in Proceedings of the Sustainable Construction Materials And Technologies, Kyoto, Japan, August 2013.

[137] World Steel Association, Steel Statistical Yearbook 2018, World Steel Association, Brussels, Belgium, 2018.

[138] G. Du and R. Karoumi, "Life cycle assessment of a railway bridge: comparison of two superstructure designs," Structure and Infrastructure Engineering, vol. 9, no. 11, pp. 1149-1160, 2013.

[139] C. J. Milani and M. Kripka, "Evaluation of short span bridge projects with a focus on sustainability," Structure and Infrastructure Engineering, vol. 16, no. 2, pp. 367-380, 2020.

[140] B. C. Lippiatt, "Selecting cost-effective green building products: bees approach," Journal of Construction Engineering and Management, vol. 125, no. 6, pp. 448-455, 1999.

[141] M. Goedkoop, R. Heijungs, M. Huijbregts, A. De Schryver, J. Struijs, and R. Van Zelm, ReCiPe 2008, Ministerie van Volkshuisvesting, Amsterdam, Netherlands, 2009.

[142] C. Hwang and K. Yoon, Multiple Attribute Decision Making: Methods and Applications, A State of the Art Survey, Springer, Berlin, Germany, 1981.

[143] L. Rosén, P.-E. Back, T. Söderqvist et al., "Score: a novel multi-criteria decision analysis approach to assessing the sustainability of contaminated land remediation," Science of The Total Environment, vol. 511, pp. 621-638, 2015.

[144] R. Sebastian, C. Claeson-Jonsson, and R. Di Giulio, "Performance-based procurement for low-disturbance bridge construction projects," Construction Innovation, vol. 13, no. 4, pp. 394-409, 2013.

[145] K. Ek, "Multi-criteria decision analysis methods to support sustainable infrastructure construction,” 2019.
[146] R. W. Saaty, "The analytic hierarchy process-what it is and how it is used," Mathematical Modelling, vol. 9, no. 3-5, pp. 161-176, 1987.

[147] S. Opricovic and G. H. Tzeng, "Compromise solution by MCDM methods: a comparative analysis of VIKOR and TOPSIS," European Journal of Operational Research, vol. 156, no. 2, pp. 445-455, 2004.

[148] V. Penadés-Plà, V. Yepes, and T. García-Segura, "Robust decision-making design for sustainable pedestrian concrete bridges," Engineering Structures, vol. 209, Article ID 109968, 2019.

[149] V. Penadés-Plà, T. García-Segura, and V. Yepes, "Robust design optimization for low-cost concrete box-girder bridge," Mathematics, vol. 8, no. 3, p. 398, 2020.

[150] M. Greenacre, Correspondence Analysis in Practice, CRC Press, Boca Raton, FL, USA, third edition, 2017. 